\title{
PREPARATION AND STABILITY ASSESSMENT OF PERILLA FRUTESCENS SEED OIL POWDER
}

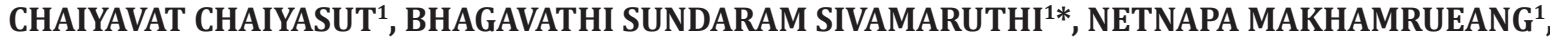 \\ PERIYANAINA KESIKA ${ }^{1}$, SASITHORN SIRILUN ${ }^{1}$, SARTJIN PEERAJAN ${ }^{2}$
}

\begin{abstract}
${ }^{1}$ Faculty of Pharmacy, Innovation Center for Holistic Health, Nutraceuticals and Cosmeceuticals, Chiang Mai University, Chiang Mai 50200, Thailand. ${ }^{2}$ Health Innovation Institute, Chiang Mai 50230, Thailand. Email: sivasgene@gmail.com
\end{abstract}

Received: 28 July 2017, Revised and Accepted: 18 September 2017

ABSTRACT

Objective: The present study deals with the preparation and stability assessment of Perilla frutescens seed oil powder (PSOP) by spray drying technique.

Methods: Perilla oil emulsion was prepared with various combinations of emulsifiers and maltodextrin powder. The emulsion was dried in a spray dryer, and dried samples were packed and stored at 4,25 , and $40^{\circ} \mathrm{C}$ for 3 months. The changes in acid and peroxide value the fatty acid content of PSOP during storage were assessed. PSOP samples were subjected to scanning electron microscopic analysis to examine the size and shape of the particle.

Results: About $9.52 \%$ of PSOP yield was obtained while $5 \%$ of whey protein was used as an emulsifier. The moisture content of the PSOP was $2.06 \pm$ 0.23-3.08 \pm 0.13\%. The acid and peroxide values were increased from $1.49 \pm 0.09$ to $3.71 \mathrm{mg} \mathrm{KOH} / \mathrm{g}$ of PSOP, $4.10-7.18 \mathrm{mEq} / \mathrm{kg}$ of PSOP, while stored in aluminum foil and kept at $40^{\circ} \mathrm{C}$. About $39.97,26.68,24.78$, and $7.47 \%$ of linolenic, oleic, linoleic, and palmitic acids were found in PSOP, respectively.

Conclusion: The study revealed that spray-dried PSOP was stable when stored in the absence of light and air at low temperature. The spray-dried PSOP is the best candidate for pharmacological and food applications.

Keywords: Fatty acid, Perilla frutescens, Spray drying technique, Scanning electron microscopy.

(C) 2017 The Authors. Published by Innovare Academic Sciences Pvt Ltd. This is an open access article under the CC BY license (http://creativecommons. org/licenses/by/4. 0/) DOI: http://dx.doi.org/10.22159/ajpcr.2017.v10i12.21672

\section{INTRODUCTION}

Perilla frutescens (L.) Britton is an annual herbaceous plant and used as a traditional medicine in Asian countries for years. The perilla seed (PS) and PS oil (PSO) are rich sources of phenolic compounds, antioxidants, and polyunsaturated fatty acids (especially, $\alpha$-linolenic acid, linoleic acid, oleic acid, and palmitic acid). Several reports revealed that the PS, PSO, and perilla leaves have antioxidant, antiallergic, antiinflammatory, anticancer, neuroprotective, and $\alpha$-glucosidase inhibitory properties [1-4]. PSO is commonly used to flavor the foods, and as cooking oil (particularly in Korean cuisine), and in cleansing products.

In general, plant-based oils are vulnerable to isomerization and oxidation during processing and storage due to the presence of unsaturated fatty acids. Thus, the prevention of the degradation of the bioactive components in the oil is important to maintain the quality of the oil [5].

The conversion of oil into powder form by drying methods such as freeze dry and spray dry is one of the ways to preserve and store the oil efficiently. The spray drying of oil improved the handling and stabilizing the essential fatty acids present in the oil and extends the storage/ shelf life. Several spray-dried powders of emulsified oils; fats are used in food industries [6].

The carrier matrixes (CM) were utilized in the spray drying process to facilitate the powderization. Further, emulsification of oil is performed in many cases before spray drying. The CM are selected based on the stability, solubility, yield, and absorbency. The maltodextrin (MD), lactose, cyclodextrin, starch, and modified starch are commonly served as CM. The stability of dry emulsions with MD, lactose, and mannitol was reported and revealed that it facilitates the crystalline [7]. The spraydried Myracrodruon urundeuva Allemão extract retain its bioactivities, and author claimed that spray drying method provides an adequate amount of dry powdered extract [8].

The storage conditions significantly affect the quality of the product. The factors such as sunlight, temperature, oxygen content influence the bioactivity, and quality of the spray-dried powders. In general, the rate of degradation process is high in the foods with high unsaturated fatty acids. Decomposition led the product to become unfeasible, and/or affect the flavor, color, and nutritional value of the food [9]

PS and PSO are used in pharmacological preparation because of the valuable nutraceutical property of perilla. Thus, the current study was aimed to formulate and produce the PSO powder (PSOP) by the spray drying method. Further, the present study explains about the stability of PSOP while stored at different temperature and conditions for 3 months.

\section{METHODS}

\section{Raw materials}

The cold pressed perilla (P. frutescens [L.] Britton) seed oil (PSO) was purchased from Energy Friend Ltd., Part. (Chiang Mai, Thailand) and stored at $4^{\circ} \mathrm{C}$ until use. MD powder (with dextrose equivalent of 11.08) was obtained from WGC Co., Ltd., Nakornpatom, Thailand, which is used to increase the texture of the final product. Whey protein isolate (WPI) was also obtained from WGC Co., Ltd. (Nakornpatom, Thailand). Emultec 908 (E908) was obtained from Siam Modified Starch Corporation Co., Ltd., Pathum Thani, Thailand.

\section{Preparation of PSOP by spray drying method}

The composition of the emulsion was PSO (30 and 40\%) and MD (15 and $20 \%)$ and an emulsifier such as E908 (2\% and $5 \%)$ and WPI (2\% and $5 \%$ ) (Table 1). 
The ingredients of the emulsion were dissolved in deionized water at $50^{\circ} \mathrm{C}$. Then, it was mixed thoroughly using high shear laboratory mixer (Silverson, L5M-A, Buckinghamshire, England) at $7000 \mathrm{rpm}$ for 3 minutes. The viscosity of the emulsion was measured using Rheometer (Brookfield, R/S-CPS, Middleboro, MA). The emulsion was dried in spray dryer (Lab Plant, Spray drier SD-04, North Yorkshire, England) at $180^{\circ} \mathrm{C}$ (inlet temperature), and $90^{\circ} \mathrm{C}$ (outlet temperature) with the inlet flow rate of $3 \mathrm{rpm}$. After that, the powder was cooled to room temperature. The collected powders were preserved in several storage conditions until use. The percentage of yield was calculated as detailed previously [4]

\section{Storage condition of PSOP}

About $5 \mathrm{~g}$ of PSOP were packed into an aluminum foil bag (AFB) and amber glass bottle (AGB). The packed samples were stored at different temperatures $\left(4^{\circ} \mathrm{C}, 25^{\circ} \mathrm{C}\right.$, and $\left.40^{\circ} \mathrm{C}\right)$ for 3 months. During storage, the samples were withdrawn every month to measure the acid and peroxide values. The fatty acid content of the samples was analyzed only at the month of 0 (severed as control) and 3 .

\section{Viscosity and moisture content analysis}

The moisture content of PSOP was determined using a moisture analyzer (MS-50, A\&D, Tokyo, Japan) at $160^{\circ} \mathrm{C}$. The viscosity of emulsion was determined using cylindrical spindles by R/S Rheometer (Brookfield, R/S-CPS, Middleboro, MA, USA)

\section{Determination of acid and peroxide value}

The acid and peroxide values of PSOP were determined according to Sirilun et al. [4]. The acid and peroxide values were represented as $\mathrm{mg}$ of potassium hydroxide equivalent per gram of PSOP (mg KOH/g of

Table 1: The composition of the emulsions

\begin{tabular}{llllll}
\hline \multirow{2}{*}{ Recipe } & \multicolumn{2}{l}{ Composition (\%) } & \multicolumn{2}{l}{} \\
\cline { 2 - 6 } & Water & PSO & MD & \multicolumn{2}{l}{ Emulsifier } \\
\cline { 3 - 6 } & & & & E908 & Whey protein \\
\hline 1 & 53 & 30 & 15 & 2 & - \\
2 & 50 & 30 & 15 & 5 & - \\
3 & 53 & 30 & 15 & - & 2 \\
4 & 50 & 30 & 15 & - & 5 \\
5 & 48 & 30 & 20 & 2 & - \\
6 & 45 & 30 & 20 & 5 & - \\
7 & 48 & 30 & 20 & - & 2 \\
8 & 45 & 30 & 20 & - & 5 \\
9 & 43 & 40 & 15 & 2 & - \\
10 & 40 & 40 & 15 & 5 & - \\
11 & 43 & 40 & 15 & - & 2 \\
12 & 40 & 40 & 15 & - & 5 \\
13 & 38 & 40 & 20 & 2 & - \\
14 & 35 & 40 & 20 & 5 & - \\
15 & 38 & 40 & 20 & - & 2 \\
16 & 35 & 40 & 20 & - & 5 \\
\hline
\end{tabular}

E908: Emultec 908, MD: Maltodextrin, PSO: Perilla seed oil
PSOP), and milliequivalent of oxygen per kilogram of PSOP (mEq/Kg of PSOP), respectively.

\section{Quantification of individual fatty acid content}

The individual fatty acid content was measured as described in the previous report [4] and outsourced at Halal Science Center, Chulalongkorn University, Bangkok, Thailand.

\section{Scanning electron microscopy (SEM)}

The surface structure of PSOP was observed by LV-SEM (JEOL, JSM5910LV, Tokyo, Japan). The PSOP was coated with a very thin layer of gold using Sputter coater (SPI-Module, West Chester, PA), before the microscopic examination.

\section{Statistical analysis}

All the experiments were performed in triplicates except fatty acid analysis, and the results were represented as mean \pm SD. The statistical significance of the data was assessed by one-way ANOVA. Duncan's new multiple range test determined significant differences, at the $95 \%$ confidential level $(\mathrm{p}<0.05)$ using statistical SPSS software version 17.0 (SPSS Inc., Chicago, USA).

\section{RESULTS AND DISCUSSION}

\section{Preparation and evaluation of PSOP}

The purchased PSO was clear and yellow (Fig. 1a). The total of 16 oil emulsion formulas was prepared with various combinations of emulsifier, MD, and PSO. The viscosity of all the formulas was analyzed. The viscosity of the emulsions was found to be varied from $0.25 \pm 0.007$ to $5.87 \pm 0.1$ Pa.s. The high viscosity of about $5.87 \mathrm{~Pa}$. s was observed in the recipe no. 14 (Fig. 2).

Relatively high viscous emulsions were not subjected to spray drying process due to the nozzle pore size (high viscous samples are not able to flow through the nozzle of the spray dryer). Thus, recipe no. $1,3,4,5,7,8,9,11,12$, and 15 were subjected to a spray drying process to yield the powder. The representative PSOP samples were shown in Fig. 1b. The surface structure of the PSOP was microscopically analyzed (Fig, 3a-g) and found that the size of PSOP was 30-44 nm (Fig. 3a).

The powder yield of PSOP was significantly affected by the emulsifier and MD concentration. To the maximum of $9.52 \%$ yield of PSOP was obtained in the recipe 8 , in which $5 \%$ of whey protein was used as an emulsifier (Table 2). The moisture content of the PSOP was ranging between $2.06 \pm 0.23$ and $3.08 \pm 0.13 \%$ (Table 2 )

The acid value represents the triglyceride content in an oil sample, which is an indicator of degradation and rancidity of oil. As per the Thai Ministry of Public Health Notification (2000), the acceptable level of acid value is less than $4 \mathrm{mg} \mathrm{KOH} / \mathrm{g}$ of oil. The acid value of the PSOP was analyzed and found that the recipe no. 15 has the acid value of about $4.38 \pm 0.34 \mathrm{mg} \mathrm{KOH} / \mathrm{g}$ of PSOP. While other recipes showed the acid value within the acceptable range except recipe no. 11 and 15 (Table 2).

Table 2: The yield, moisture content, acid value, and peroxide value of PSOP

\begin{tabular}{|c|c|c|c|c|}
\hline Recipe & Yield (\%) & Moisture content (\%) & Acid value (mg КОН/g PSOP) & Peroxide value (mEq/kg PSOP) \\
\hline 1 & $3.61^{c} \pm 0.16$ & $3.08^{\mathrm{d}} \pm 0.13$ & $1.56^{\mathrm{a}} \pm 0.12$ & $4.10^{\mathrm{a}} \pm 0.08$ \\
\hline 3 & $3.55^{c} \pm 0.08$ & $2.65^{\mathrm{c}} \pm 0.10$ & $1.70^{\mathrm{a}} \pm 0.16$ & $4.55^{\mathrm{bc}} \pm 0.15$ \\
\hline 4 & $6.06^{\mathrm{d}} \pm 0.10$ & $2.50^{\mathrm{bc}} \pm 0.15$ & $1.46^{\mathrm{a}} \pm 0.12$ & $4.70^{c} \pm 0.09$ \\
\hline 5 & $1.75^{\mathrm{a}} \pm 0.35$ & $2.80^{\mathrm{cd}} \pm 0.25$ & $2.20^{\mathrm{b}} \pm 0.05$ & $4.46^{\mathrm{bc}} \pm 0.08$ \\
\hline 7 & $2.41^{\mathrm{b}} \pm 0.12$ & $2.26^{\mathrm{ab}} \pm 0.16$ & $1.57^{\mathrm{a}} \pm 0.23$ & $4.79^{c} \pm 0.11$ \\
\hline 8 & $9.52^{\mathrm{e}} \pm 0.70$ & $2.50^{\mathrm{bc}} \pm 0.24$ & $1.49^{\mathrm{a}} \pm 0.09$ & $4.35^{\mathrm{ab}} \pm 0.35$ \\
\hline 9 & $1.64^{\mathrm{a}} \pm 0.37$ & $2.06^{\mathrm{a}} \pm 0.23$ & $2.56^{\mathrm{bc}} \pm 0.37$ & $4.35^{\mathrm{ab}} \pm 0.16$ \\
\hline 12 & $1.25^{\mathrm{a}} \pm 0.24$ & $2.61^{\mathrm{bc}} \pm 0.21$ & $2.75^{c} \pm 0.17$ & $5.23^{\mathrm{d}} \pm 0.07$ \\
\hline 15 & $3.48^{c} \pm 0.12$ & $2.47^{\mathrm{bc}} \pm 0.24$ & $4.38^{\mathrm{d}} \pm 0.34$ & $6.37^{\mathrm{e}} \pm 0.33$ \\
\hline
\end{tabular}

a-e Indicates the significant difference between the values. PSOP: Perilla frutescens seed oil powder 


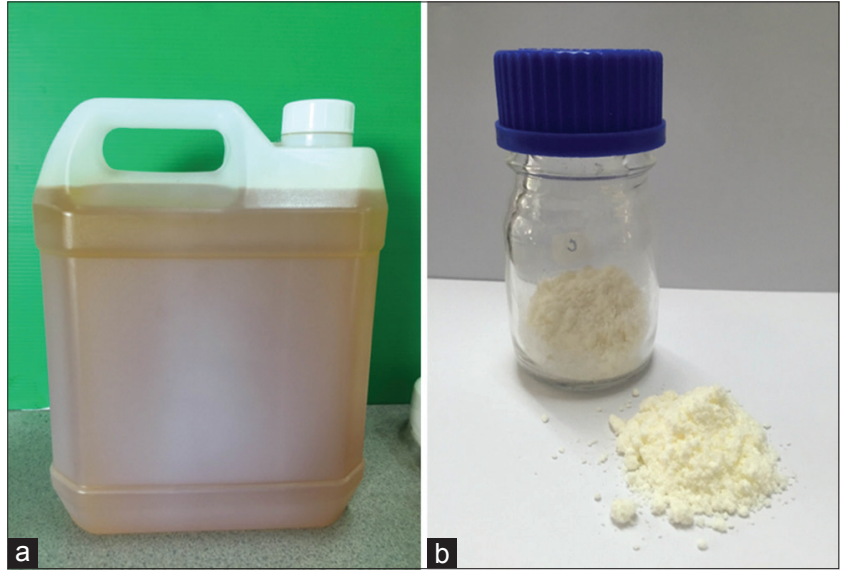

Fig. 1: Perilla seed oil (a) and perilla seed oil powder (b)

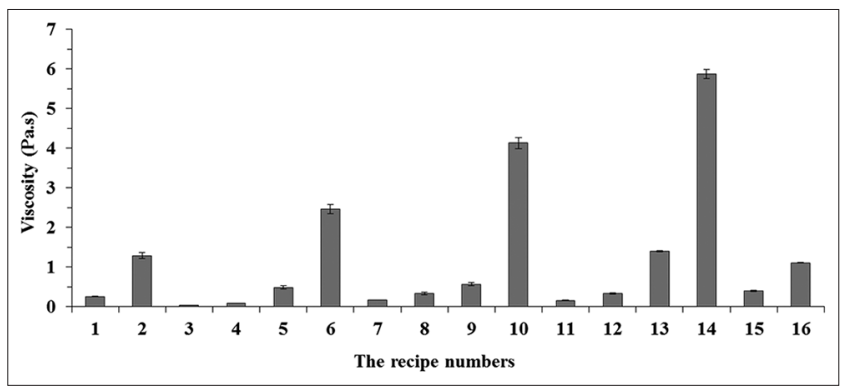

Fig. 2: The viscosity of emulsions. The values are represented as mean \pm standard deviation

Likely, peroxide values are used as an indicator of oxidation of the oil. As per the Thai Ministry of Public Health Notification (2000), the standard level of peroxide is $<10 \mathrm{mEq} / \mathrm{kg}$ of oil. The prepared PSOP has fallen in the safe range of peroxide value (Table 2).

\section{Stability study}

The PSOP prepared from the recipe no. 8 was selected for stability study since it yielded high powdered oil. The PSOP samples were stored at different temperature and in different storage containers. The changes in the acid and peroxide values were assessed at $0,1,2$, and 3 months of storage, whereas fatty acid content was assessed at 0,1 , and 3 months of storage.

The initial acid value (control) of PSOP was $1.49 \pm 0.09 \mathrm{mg} \mathrm{KOH} / \mathrm{g}$ of PSOP. The results indicated that when the storage time increased, the acid value also increased in the samples. To the maximum of $3.71 \mathrm{mg} \mathrm{KOH} / \mathrm{g}$ of PSOP acid value was observed in the samples that are stored in aluminum foil and kept at $40^{\circ} \mathrm{C}$ (Fig. 4a). The increase in the acid value is possibly due to the high temperature which affects the glycerol and free fatty acids in oil powder. Moreover, aluminum foil is porous enough for the oxygen passage [5]. The samples stored in amber bottles showed relatively low acid values.

The peroxide values are directly related to the autoxidation of oil, especially occurred in the oil enriched with unsaturated fatty acid. Moreover, the unsaturation levels were assessed by iodine/peroxide values. The presence of iodine and oxidation leads to rancidity. The initial peroxide value (control) of PSOP was $4.10 \mathrm{mEq} / \mathrm{kg}$ of PSOP. Similar to acid value, the maximum of $7.18 \mathrm{mEq} / \mathrm{kg}$ of PSOP peroxide value was observed in the samples that are stored in aluminum foil and kept at $40^{\circ} \mathrm{C}$. The samples stored in amber bottles showed relatively low peroxide values (Fig. $4 \mathrm{~b}$ ).

Alpha-linolenic acid, oleic acid, linoleic acid, and palmitic acid are the major of fatty acids present in PSO [4]. The PSOP has 39.97, 26.68, 24.78 , and $7.47 \%$ of linolenic acid, oleic acid, linoleic acid, and palmitic
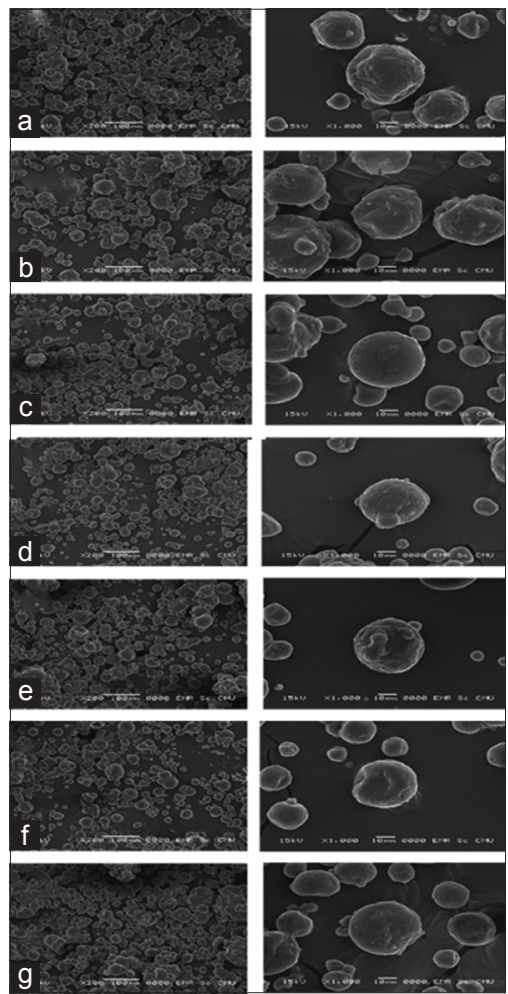

Fig. 3: Scanning electron microscopic pictures of PSOP stored at different conditions for 3 months. The images were taken at $200 \times$ and $1000 \times$ magnifications. (a) Control at 0 month, (b) PSOP stored in aluminum foil bag at $4^{\circ} \mathrm{C}$, (c) stored in aluminum foil bag at $25^{\circ} \mathrm{C}$, (d) stored in aluminum foil bag at $40^{\circ} \mathrm{C}$, (e) stored in amber glass bottle at $4^{\circ} \mathrm{C}$, (f) stored in amber glass bottle at $25^{\circ} \mathrm{C}$, and $(\mathrm{g})$ stored in amber glass bottle at $40^{\circ} \mathrm{C}$

acid, respectively. The influence of storage temperature and container on the fatty acid composition of PSOP was assessed (Table 3), and the results revealed that the fatty acid content was not significantly affected during storage when compared to that of the control.

After 3 months of storage, the PSOP was subjected to microscopic observation. The particle size of the PSOP was not significantly affected (Fig. 3), which indicated that the tested storage conditions caused no damage in the structure and size of the perilla oil powder.

Hui-Juan et al. [10] reported that more than 30\% embedding rate was achieved by preparing PSOP using cross-linked esterified porous starch. This powdering method also extended the time for lipid peroxidation in PSOP when compared to that of the PSO. Dachuan et al. [11] reported that the $95 \%$ embedding efficiency was attained by preparing PSOP with MD and soybean isolate through emulsification and spray drying method at optimum conditions. Kha et al. [5] reported the stability of microencapsulated GAC oil powder at different storage conditions and proved that the encapsulated GAC oil powder is stable when stored at low temperatures particularly in the absence of air and light. In the present study, PSOP was prepared by emulsification and spray drying method, and analysis of the stability of PSOP at different storage conditions suggested that storage of PSOP in airtight AGB at $4^{\circ} \mathrm{C}$, prevent the oxidation, and preserve the nutritional value of PSOP.

\section{CONCLUSION}

The present study employed emulsification and the spray drying technique to produce PSOP. The yield of the PSOP was too low to further proceed to industrial level production. However, the desirable qualities of the PSO, especially nutritional values, are preserved by powderization process. The storage and stability study revealed that 
Table 3: Fatty acid content of PSOP stored at various storage conditions for 3 months. Control samples were analyzed for fatty acid content immediately after the preparation of PSOP

\begin{tabular}{|c|c|c|c|c|c|c|}
\hline \multicolumn{3}{|c|}{ Storage condition } & \multicolumn{4}{|c|}{ Representative fatty acids (\%) } \\
\hline Duration & Packaging & $\operatorname{Temp}\left({ }^{\circ} \mathrm{C}\right)$ & Linolenic acid & Oleic acid & Linoleic acid & Palmitic acid \\
\hline Control (0 h) & & & 39.97 & 26.68 & 24.78 & 7.47 \\
\hline \multirow[t]{3}{*}{ After 1 month } & Stored in aluminum foil bag & 4 & 38.57 & 25.48 & 26.19 & 7.41 \\
\hline & & 25 & 38.35 & 25.64 & 25.65 & 7.61 \\
\hline & & 40 & 36.48 & 23.99 & 29.24 & 7.13 \\
\hline \multirow[t]{3}{*}{ After 3 months } & Stored in amber glass bottle & 4 & 38.44 & 25.36 & 25.47 & 7.51 \\
\hline & & 25 & 38.79 & 25.85 & 24.62 & 7.75 \\
\hline & & 40 & 38.56 & 25.96 & 24.70 & 7.68 \\
\hline
\end{tabular}

PSOP: Perilla frutescens seed oil powder

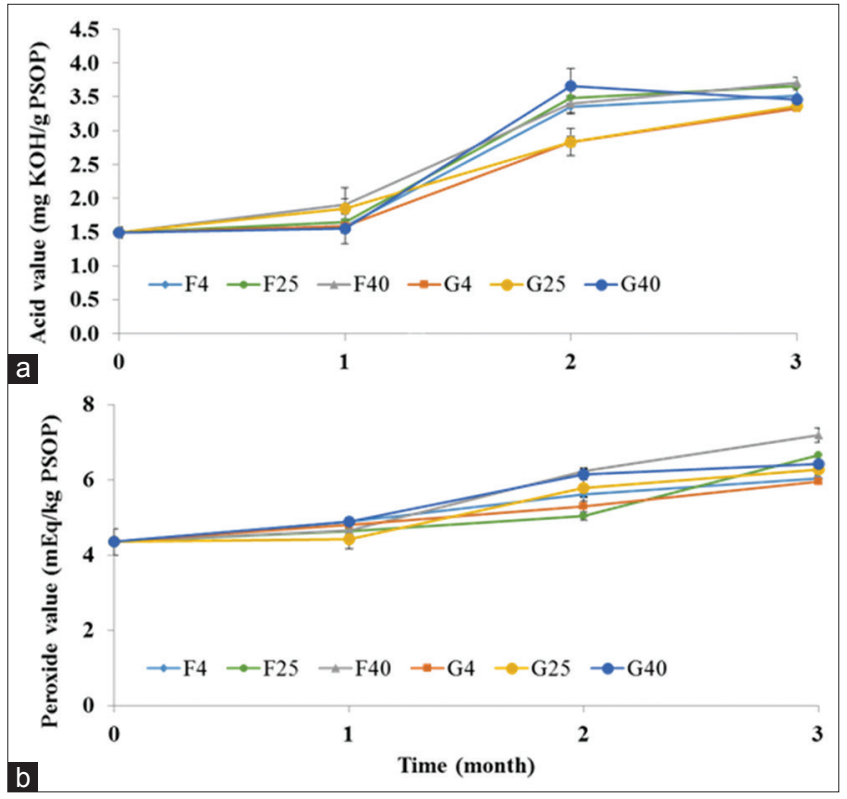

Fig. 4: The acid (a) and peroxide (b) values of PSOP stored at different conditions. F4: Stored in aluminum foil at $4^{\circ} \mathrm{C}$, F25: Stored in aluminum foil at $25^{\circ} \mathrm{C}, \mathrm{F} 40$ : Stored in aluminum foil at $40^{\circ} \mathrm{C}, \mathrm{G} 4$ : Stored in amber glass bottle at $4^{\circ} \mathrm{C}, \mathrm{G} 25$ : Stored in amber glass bottle at $25^{\circ} \mathrm{C}$, and G40: Stored in amber glass bottle at $40^{\circ} \mathrm{C}$

spray-dried PSOP was stable, especially when stored in the absence of light and air at low temperature. Further, investigation on the carrier and emulsifier is required to improve the yield of PSOP. The spray-dried PSOP is the best candidate for pharmacological and food applications.

\section{ACKNOWLEDGMENT}

Authors gratefully acknowledge the Chiang Mai University grant (CMUgrant) for the financial support. Authors also acknowledge the Faculty of Pharmacy and Chiang Mai University, Thailand, for the support and instrumentation facilities.

\section{REFERENCES}

1. Kim MJ, Kim HK. Perilla leaf extract ameliorates obesity and dyslipidemia induced by high-fat diet. Phytother Res 2009;23(12):1685-90.

2. Ito N, Nagai T, Oikawa T, Yamada H, Hanawa T. Antidepressant-like Effect of 1-perillaldehyde in stress-induced depression-like model mice through regulation of the olfactory nervous system. Evid Based Complement Alternat Med 2011;2011:512697.

3. Ahn H, Kim J, Kim J, Auh J, Choe E. In vitro $\alpha$-glucosidase and pancreatic lipase inhibitory activities and antioxidants of samnamul (Aruncus dioicus) during rehydration and cooking. Food Sci Biotechnol 2014:23:1287-93.

4. Sirilun S, Sivamaruthi BS, Pengkumsri N, Saelee M, Chaiyasut K, Tuntisuwanno $\mathrm{N}$, et al. Impact of different pre-treatment strategies on the quality of fatty acid composition, tocols content and metabolic syndrome related activities of Perilla frutescens seed oil. J Appl Pharm Sci 2016;6(2):1-8

5. Kha TC, Nguyen MH, Roach PD, Stathopoulos CE. A storage study of encapsulated gac (Momordica cochinchinensis) oil powder and its fortification into foods. Food Bioprod Process 2015;96:113-25.

6. Furuta T, Soottitantawat A, Neoh TL, Yoshii H. Effect of microencapsulation on food flavors and their releases. In: Devahastin S, editor. Physicochemical Aspects of Food Engineering and Processing. Florida: CRC Press; 2010. p. 3-40.

7. Matsuura T, Ogawa A, Tomabechi M, Matsushita R, Gohtani S, Neoh TL, et al. Effect of dextrose equivalent of maltodextrin on the stability of emulsified coconut-oil in spray-dried powder. J Food Eng 2015; 163:54-9.

8. Leite RD, de Souza VG, de Oliveira AH, Júnior JV, Salvador ID, de Andrade FH, et al. Standardization and stability evaluation of dry extracts of Myracrodruon urundeuva allemao obtained by a spray drier. Int J Pharm Pharm Sci 2017;9(2):154-9.

9. Robertson RL. Food Packaging: Principles and Practice. $2^{\text {nd }}$ ed. Boca Raton, FL: CRC Press; 2006.

10. Hui-Juan J, Xiao-Lan L, Gan-Hui H. Preparation of perilla seed oil powder and its antioxidant activity. Food Sci 2013;34(12):95-8.

11. Dachuan L, Jiangping L, Ye L, Yonggang H, Xian Z. Preparation of perilla seed oil powder. China Oils Fats 2008;11:5-8. 